\title{
Design feedback controller of six pulse three phase rectifier based on differential evolution algorithm
}

\author{
Herlambang Setiadi ${ }^{1}$, Akbar Swandaru ${ }^{2}$, Teguh Aryo Nugroho ${ }^{3}$ \\ ${ }^{1}$ Faculty of Advanced Technology and Multidisipline, Universitas Airlangga, Surabaya, Indonesia \\ ${ }^{2}$ ASEAN Centre for Energy, Jakarta, Indonesia \\ ${ }^{3}$ Department of Electrical Engineering, Universitas Pertamina, Jakarta, Indonesia
}

\begin{tabular}{l} 
Article Info \\
\hline Article history: \\
Received Oct 22, 2020 \\
Revised Mar 10, 2021 \\
Accepted Mar 24, 2021 \\
\hline
\end{tabular}

Keywords:

DEA

PID controller

Renewable energy

Six pulse rectifier

\begin{abstract}
The application of power electronics devices is increasing significantly in this past few year. This condition could happen due to the development of semiconductor technology. The application of power electronics is varied from power plant application to vehicles application. One of the power electronics devices that becoming popular is rectifier. Rectifier can be used to transform AC electricity to DC. This paper presents fully controlled six pulse three phase rectifier which designed to stabilize the DC voltage output on a certain loads variation. PID controller is used as the close loop controller system of the rectifier. To get optimal coordination differential evolution algorithm is used to tune the parameter of PID controller. simulation is carried out in MATLAB/SIMULINK environment. From the simulation results, it is found that the performance of six pulse three phase rectifier can be enhanced significantly by using PID controller based on differential evolution algorithm.
\end{abstract}

This is an open access article under the CC BY-SA license.

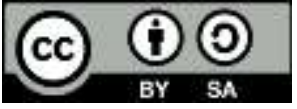

Corresponding Author:

Herlambang Setiadi

Faculty of Advanced Technology and Multidicipline

Universitas Airlangga

Campus C UNAIR Gedung Kuliah Bersama, Mulyorejo, Surabaya, Indonesia

Email: h.setiadi@stmm.unair.ac.id

\section{INTRODUCTION}

In this recent year the application of power electronics devices are increased significantly due to the integration of renewable energy, battery energy storage and electric vehicles charging station [1]-[4]. Power electronics can be used to transform natural energy of renewable energy (wind and solar) into electricity. Power electronics could also be used to enhance the energy efficiency and power loss. The application of power electronics devices for enhancing power quality in distributed generation is reported in [5]. In [5], it is noticeable that power electronics could handle sag, swell and harmonics problems. Research effort in [6], focused on the application of boost converter as the devices in fuel cell. The application of multi-level inverter as buffer of PV generation and grid is reported in [7]. From three research above it is noticeable that power electronics devices are very crucial in modern power systems.

Six pulse three phase rectifier can be used to transform AC electricity into DC electricity. This device can be used as one of battery energy storage and electric vehicles charging station devices. Rectifier is also used in high voltage DC transmission line. The purpose of six pulse three phase rectifier is to maintain the DC output at a certain level on certain condition [8]. Hence, it is important to design the controller of this rectifier. Commonly, the controller of this rectifier is PID controller. However, with more and more new technology integrated to the grid conventional PID controller may not be sufficient to handle the complexity 
and the non-linearity of modern power grid. Hence, designing the PID controller based on the smart method (based on artificial intelligence) is inevitable.

Fuzzy logic, metaheuristic algorithm and neural network fall under artificial intelligence (AI). The application of multiscale visual object detection for unsupervised ubiquitos projection based on portable projector camera system is reported in [9]. Reserch effort in [10], shows the application of extended particle filter for human hand motion recognition. For solving optimization problem, metaheuristic algorithm is better than fuzzy logic and neural network. Research in [11]-[14] explain the application of metaheuristic algoritm for optimization problems. In, [11] particle swarm optimization (PSO) is used simulataneously tune the parameter of PSS and SSSC. From their research it is found that oscillation in power system can be handle properly by designing the coordinated control of PSS and SSSC using PSO. Research effort in [12], proposed a smart way for dispatching the power plant emission by using AI approach. In this research ant colony optimization is the AI method that has been used to dispacth the power plant emission. It is found that the emission of power plant can be dispatched optimally.

GA can also be used to find the best parameter of multi-band power system stabilizer (PSS) as reported in [13]. It is found that small signal stability of power system can be enhanced by introducting multi-band PSS based on GA. In Ref. [14], differential evolution algorithm (DEA) is used to find the best place to instal thyristor controlled series capacitor (TCSC). It is found that by using DEA method, TCSC can be installed in the best place. It is well known that differential evolution algorithm has advantages in terms of lower complexity in coding and less computational effort. Hence, in this paper differential evolution algorithm is used to optimized the PID controller of six pulse three phase rectifier. The rest of the paper is organized as follows: Chapter 2 provide the mathematical representation of six pulse rectifier used in this paper. The fundamental theory and mathematical model of differential evolution algorithm are explained in Chapter 3. Chapter 4 provide result and discussion of the paper. Chapter 5 highlight the conclusion and future direction of this research.

\section{RESEARCH METHOD}

\subsection{Six pulse three phase rectifier}

One of the most important parts of the rectifier is the diodes. The diodes is used as the switching of the rectifier. Diodes will controlling the rectifier so that the rectifier will generate appropriate output. For controlling unidirectional voltage output, (MOSFET) is more appropriate than diodes. Hence, in this paper MOSFET will be used as the switching devices. The voltage output of the rectifier will depend on the firing angle of the MOSFET. The mathematical representation of neutral voltage of six pulse bridge rectifier is described using (1)-(3) [15].

$$
\begin{aligned}
& v_{a n}=v_{m} \sin \omega t \\
& v_{b n}=v_{m} \sin \left(\omega t+\frac{2 \pi}{3}\right) \\
& v_{b n}=v_{m} \sin \left(\omega t-\frac{2 \pi}{3}\right)
\end{aligned}
$$

From (1)-(3), the line to line voltage can be described. The mathematical representation of line to line voltage can be described using (4)-(6) [16]. Furthermore, the average voltage output and the root-mean-square (rms) output voltage are described using (7) and (8) [17]. Moreover, the schematic diagram of six pulse rectifier with PID controller is illustrated in Figure 1.

$$
\begin{aligned}
& v_{a b}=v_{a n}-v_{b n}=\sqrt{3} V_{m} \sin \left(\omega t+\frac{\pi}{6}\right) \\
& v_{b c}=v_{b n}-v_{c n}=\sqrt{3} V_{m} \sin \left(\omega t-\frac{\pi}{2}\right)
\end{aligned}
$$




$$
\begin{aligned}
& v_{c a}=v_{c n}-v_{a n}=\sqrt{3} V_{m} \sin \left(\omega t+\frac{\pi}{2}\right) \\
& v_{d c}=\frac{3}{\pi} \int_{\frac{\pi}{6}+\alpha}^{\frac{\pi}{2}} v_{a b} d(\omega t)=\frac{3}{\pi} \int_{\frac{\pi}{6}+\alpha}^{\frac{\pi}{2}+\alpha} \sqrt{3} V_{m} \sin \left(\omega t+\frac{\pi}{6}\right) d(\omega t)=\frac{3 \sqrt{3} V_{m}}{\pi} \cos (\alpha) \\
& v_{r m s}=\left[\frac{3}{\pi} \int_{\frac{\pi}{6}+\alpha}^{\frac{\pi}{2}+\alpha} 3 V_{m}^{2} \sin ^{2}\left(\omega t+\frac{\pi}{6}\right) d(\omega t)\right]^{\frac{1}{2}}=\sqrt{3} V_{m}\left(\frac{1}{2}+\frac{3 \sqrt{3}}{4 \pi} \cos 2(\alpha)\right)^{\frac{1}{2}}
\end{aligned}
$$

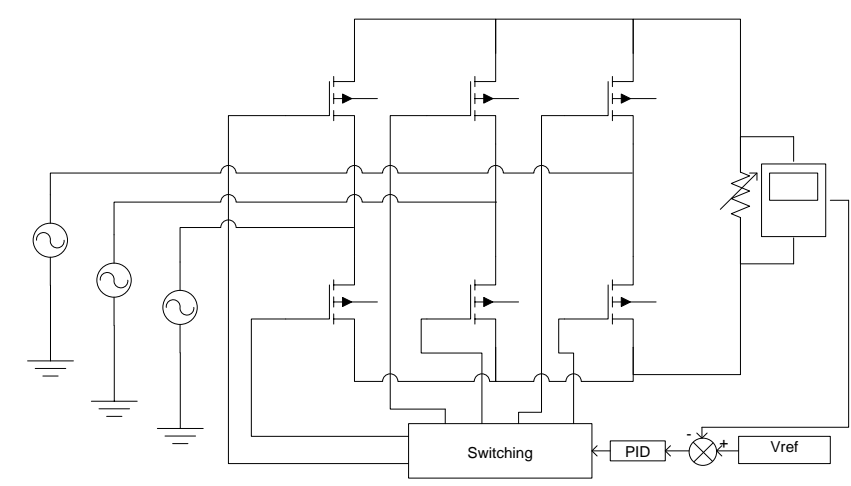

Figure 1. Fully controlled six pulse three phase rectifier equiped with PID loop back

\subsection{Differential evolution algorithm}

Differential evolutionary algorithm (DEA) is a population-based search method that uses looping cycles of recombination and selection to lead the population towards the global optimum value. This method was introduced by Storn and Price in 1995 [14]. DEA use a pair of vector population with the D-dimensional parameter. Initial population, $\mathrm{Px}$, consisting of the vector $\mathrm{x}_{\mathrm{i}, \mathrm{g}}$ as the initial point. Initial population of DEA can be modelled using (9) and (10) [18].

$$
\begin{aligned}
& P_{x g}=\left(x_{i g}\right), i=I, \ldots, N_{p}, g=I, \ldots, g_{\max } \\
& x_{i, g}=\left(x_{j, i, g}\right), j=1, \ldots, D
\end{aligned}
$$

Where $\mathrm{x}_{\mathrm{i}, \mathrm{g}}$ is the $\mathrm{i}$-th vector in the generation to $\mathrm{g}$. While $\mathrm{x}_{\mathrm{j}, \mathrm{i}, \mathrm{g}}$ is the value of the $\mathrm{i}$-th vector in the $\mathrm{j}$-th parameter, in the generation to $\mathrm{g}$. Value of $\mathrm{i}$ is an integer from 0 to $\mathrm{Np}, \mathrm{g}$ is an integer from 0 to gmax, and $\mathrm{j}$ is an integer from 0 to $\mathrm{D}-1$. The next population, $\mathrm{P}_{\mathrm{v}, \mathrm{g}}$, a population containing $\mathrm{Np}$ vector-vector are mutated randomly DE $\mathrm{V}_{\mathrm{i}, \mathrm{g}}$. This step can be described mathematically using (11) and (12) [19].

$$
\begin{aligned}
& P_{v g}=\left(v_{i g}\right), i=I, \ldots, N_{p}, g=I, \ldots, g_{\max } \\
& v_{i, g}=\left(v_{j, i, g}\right), j=1, \ldots, D
\end{aligned}
$$

Then, each vector in the initial population are recombined with the mutant vector to generate a trial population, $\mathrm{P}_{\mathrm{u}, \mathrm{g}}$, with $\mathrm{Np}$ trial vector, $\mathrm{u}_{\mathrm{i}, \mathrm{g}}$. This process can be captured through mathematical equation as described in (13) and (14) [20]. 


$$
\begin{aligned}
& P_{u g}=\left(u_{i g}\right), i=I, \ldots, N_{p}, g=I, \ldots, g_{\max } \\
& u_{i, g}=\left(u_{j, i, g}\right), j=1, \ldots, D
\end{aligned}
$$

In the process of recombination, mutant population was replaced by a population of trial in order to obtain a pair of populations, initial population (current population) and the trial population, that will be processed in a DEA. The mathematical model of DEA mutation process can be described using (15) [21].

$$
v_{i, g}=x_{r 0}+F \times\left(x_{r 10}-x_{r 20}\right)
$$

With $v_{i, g}$ is the mutant vector, $\mathrm{x}_{\mathrm{r} 1} \mathrm{X}_{\mathrm{r} 2}$ and $\mathrm{x}_{\mathrm{r} 0}$ is a vector chosen at random. $\mathrm{F}$ is a real number with range $[0,1]$. The next step of this algorithm is the crossover process. Crossover is used by DEA to form a trial vector of parameter values doubled from two different vector that is, the initial vector with the mutant vector. The mathematical representation this process can be captured using (16) [22].

$$
u_{i, g}=u_{j, i, g}=\left\{\frac{v_{j, i, g} \text { if }\left(\operatorname{rand}_{j}(0,1)\right) \leq \text { Crorj }=j_{\text {rand }}}{x_{j, i, g} \text { others }}\right.
$$

The user determine the probability of crossover based on $\mathrm{Cr}[0,1]$. To control the distribution of parameter values the probability concecpt of crossover is esential. The distribution of parameter is duplicated from the mutant parameter. To determines wheter the vector is in or not crossover, random value rand $(0.1)$ is used [23].

To determine which vector that will become member of the population for the next iteration, selection process is carried out. Conversely, the target vector will remains as a member in the next iteration, if the trial vector $\mathrm{u}_{\mathrm{i}, \mathrm{g}}$ has the fitness function better than the target vector $\mathrm{x}_{\mathrm{i}, \mathrm{g}}$. This process can be modeled using (17) [24], [25].

$$
=x_{i, g}=\left\{\frac{u_{i, g} \text { if }(u) \leq \text { Crorj }=j_{\text {rand }}}{x_{j, i, g} \text { others }}\right.
$$

\subsection{Design PID controller using DEA}

In order to investigate the performance of six pulse rectifier system with PID controller based on DEA, two different case studies in considered in this paper. In the first case study, the comparison of voltage output between six pulse rectifier with and without PID controller based on DEA is considered. The second case study focusing on the system robustness again different loading condition. All of the simulation is carried out using MATLAB/SIMULINK environment. Table 1 shows the six pulse rectifier parameter while Table 2 illustrates the DEA parameters for this simulation.

Table 1. Six pulse three phase rectifier parameters

\begin{tabular}{cc}
\hline Parameter & Value \\
\hline Voltage Source $V_{\text {line-netral }}$ & 220 Volt \\
Voltage Reference (DC) & $380 \mathrm{Volt}$ \\
System Frequency & $50 \mathrm{~Hz}$ \\
Switching Frequency & $1000 \mathrm{hz}$ \\
\hline
\end{tabular}

Table 2. DE parameters

\begin{tabular}{cc} 
Table 2 . DE & parameters \\
\hline Strategy & 1 \\
Dimension & 3 \\
Crossover & 0,8 \\
Population & 50 \\
Fitness(F) & 0,7 \\
Total Iterations & 100
\end{tabular}

In this paper, the objective function of the DEA is the minimum error of the six pulse rectifier voltage output. This objective will try to maintain the voltage output of the system near to the 380 volt (380 volt is the voltage reference. The objective of DEA method is described in (18) [26], [27].

$$
\text { Objective }=\int_{0}^{t} t\left|\Delta v_{\text {out }}(t)\right| d t
$$

\footnotetext{
Design feedback controller of six pulse three phase rectifier based on differential... (Herlambang Setiadi)
} 
Figure 2 shows the flowchart of tuning PID controller using DEA. The DEA is performed in 100 iterations. Moreover, Figure 3 shows the convergence graph of the DEA. From Figure 3 it can be seen that the DEA find their convergence value at 92 iterations. This means that the optimal PID controller value can be achieved at 92 iterations. Furthermore, at 92 iterations, the value of proportional, integral and the differential are 4.1727, 9.8304 and 0.6421 .

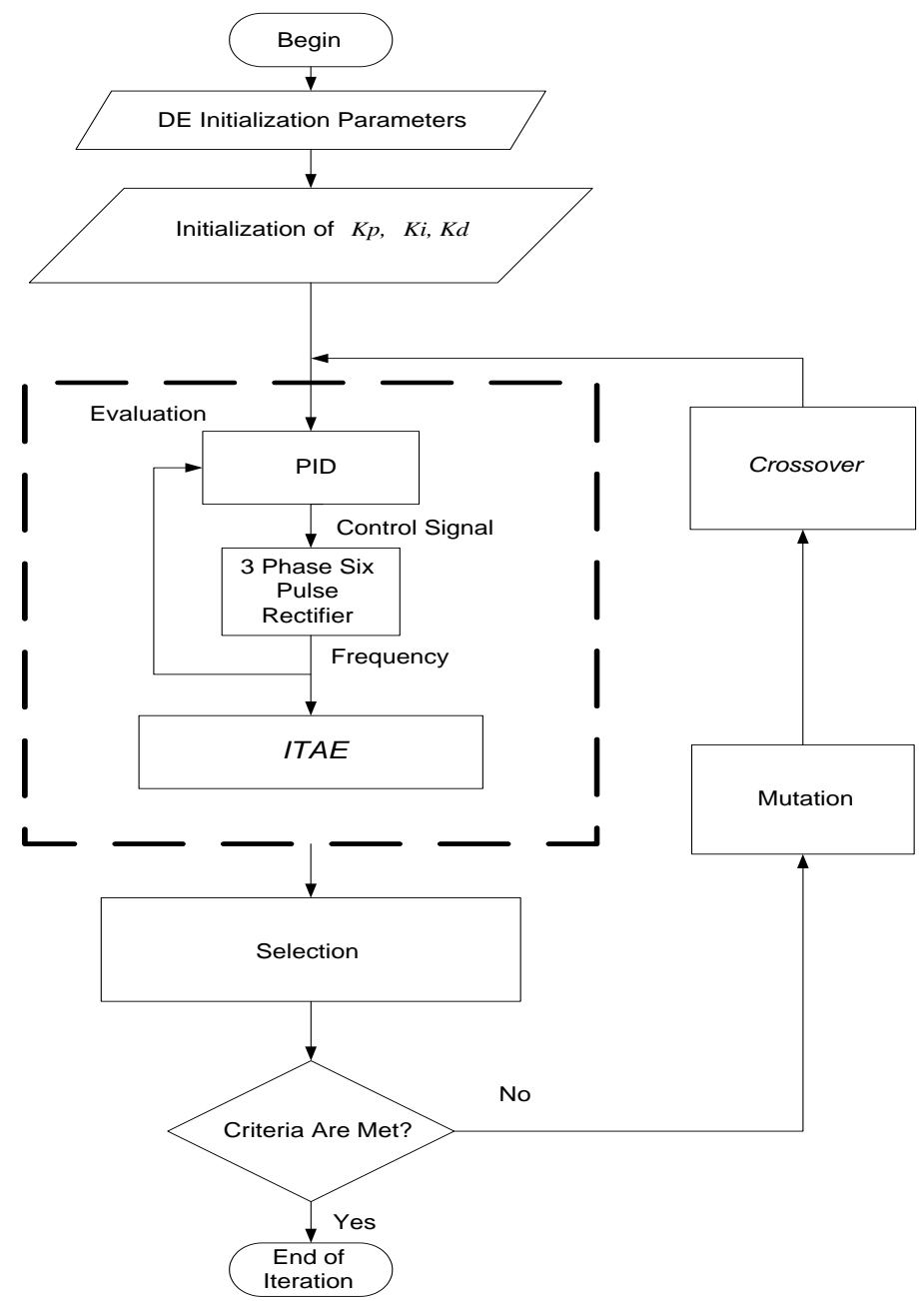

Figure 2. DE optimization flowchart

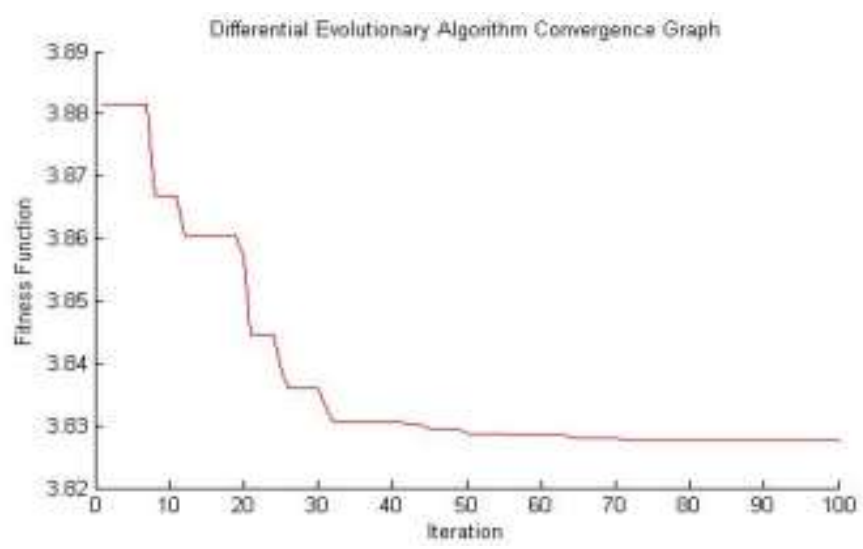

Figure 3. DEA convergence graph 


\section{RESULTS AND DISCUSSION}

\subsection{Case study 1}

In the first case study, observation of six pulse rectifier voltage output is conducted. The simulation is carried out in 1 second and $100 \mathrm{ohm}$ is set as the six pulse rectifier load. Figure 4 illustrates the voltage ouput of six pulse rectifier without PID controller. It can be observed that the system has overshoot at around 90 volt and the system experience steady state condition less that 0.1 second (settling time less than 0.1 second). However, the final value of the six pulse rectifier without PID controller is around 420 volt. Then it is unacceptable for rectifier that produce voltage output far different to the voltage reference. Hence, it is essential to add PID controller based on DEA.

The system with PID controller based on DEA response is depicted in Figure 5. From Figure 5, it can be observed that the system experience overshoot as high as the system without PID controller based on DEA. It is also found that six pulse rectifier with PID controller based on DEA experience longer settling time. However, by using PID controller based on DEA, the voltage output of the six pulse rectifier has the same value of the voltage reference. This could be happen because PID controller give an optimal signal control to the system. Hence, the switching mechanics of the rectifier are more accurate. Furthermore, by adding PID controller based on DEA in six pulse rectifier, resulting on enhancement of the rectifier performance.

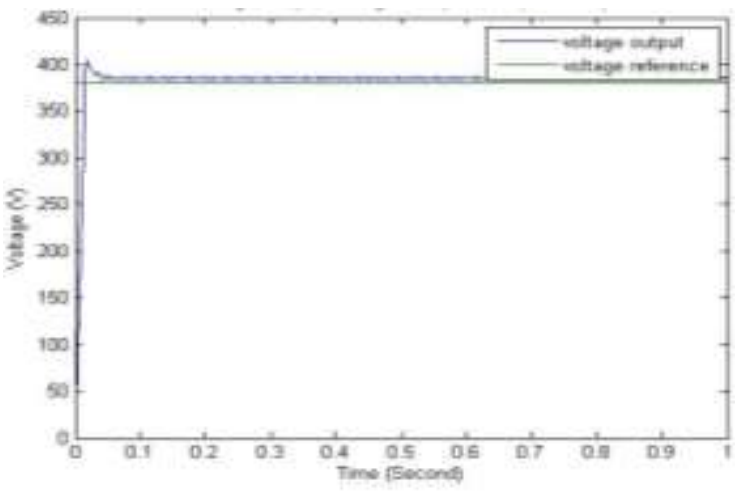

Figure 4. Voltage output comparison on system without PID loop back

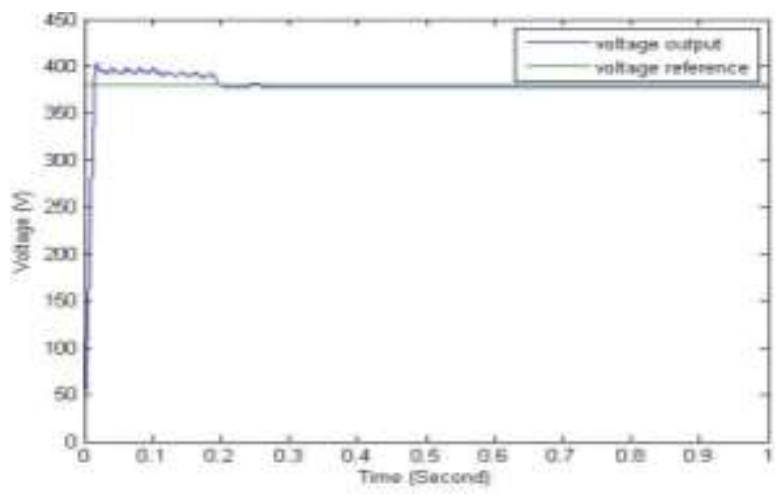

Figure 5. Voltage output comparison on system with PID loop back

\subsection{Case study 2}

In this case study, all of the six pulse rectifier system (with and without PID controller based on DEA) are tested with load variation. The load variation is varied from 10 to 100 in step of $10 \mathrm{ohm}$. The purpose of this test is to analysed the proposed controller method (PID based on DEA). Table 3 and 4 show the voltage output average and rms for both system. It is noticeable that by increasing the load, the voltage output is increase (for both condition). Furthermore, it can be observed that the voltage output of six pulse rectifier with PID based on DEA is better than without PID controller (the voltage fluctuation is smaller) as shown in Figure 6 and 7.

Table 3. Test result on system without PID

\begin{tabular}{lll}
\hline $\begin{array}{l}\text { Resistance } \\
(\text { Ohm })\end{array}$ & $\begin{array}{l}\text { Output } \mathrm{V}_{\text {avg }} \\
\text { (Volt) }\end{array}$ & $\begin{array}{l}\text { Output } \mathrm{V}_{\text {rms }} \\
\text { (Volt) }\end{array}$ \\
\hline 10 & 380.6 & 374.6 \\
20 & 383.5 & 374.6 \\
30 & 386.7 & 374.6 \\
40 & 386.7 & 377.3 \\
50 & 386.7 & 384.8 \\
60 & 386.8 & 384.9 \\
70 & 386.8 & 384.9 \\
80 & 386.8 & 384.9 \\
90 & 386.8 & 384.9 \\
100 & 386.8 & 384.9 \\
\hline
\end{tabular}

Table 4. Test result on system with optimized PID

\begin{tabular}{lll}
\hline $\begin{array}{l}\text { Resistance } \\
(\text { Ohm })\end{array}$ & $\begin{array}{l}\text { Output } \mathrm{V}_{\text {avg }} \\
(\text { Volt) }\end{array}$ & $\begin{array}{l}\text { Output } \mathrm{V}_{\text {rms }} \\
\text { (Volt) }\end{array}$ \\
\hline 10 & 377.1 & 373.1 \\
20 & 377.4 & 373.3 \\
30 & 377.5 & 373.4 \\
40 & 377.5 & 373.4 \\
50 & 377.5 & 373.4 \\
60 & 377.5 & 373.5 \\
70 & 377.5 & 373.5 \\
80 & 377.6 & 373.5 \\
90 & 377.6 & 373.5 \\
100 & 377.6 & 373.5 \\
\hline
\end{tabular}




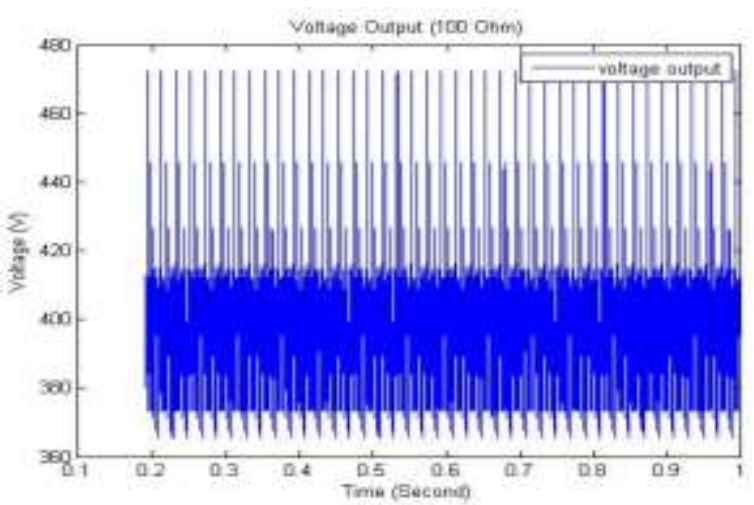

Figure 6. Voltage output system without PID loop back

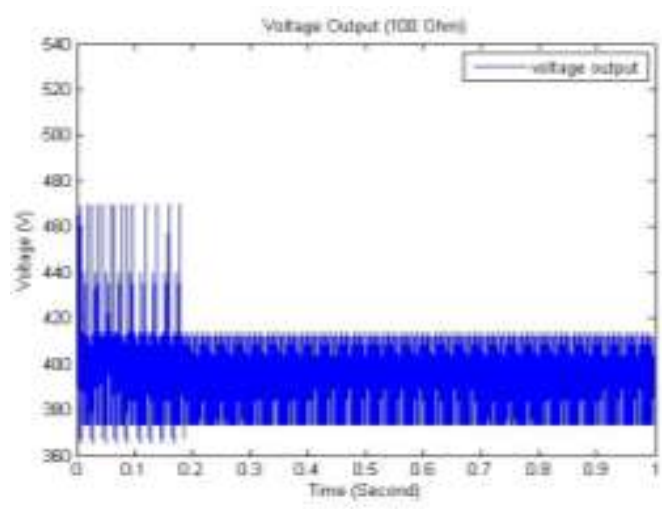

Figure 7. Voltage output system with optimized PID loop back

\section{CONCLUSION}

From simulation it is found that PID which optimized with DEA can keep the voltage average output on various load, strings from $10 \mathrm{Ohm}$ to $100 \mathrm{Ohm}$. Although it still cannot reach to the voltage reference instead of putting it near-bellow 380 Volt, the voltage average output is still relatively stable than the voltage average output of the system which without optimized PID loopback. Even though it still acceptable, the output of system with optimized PID are more reliable. The Simulation is still considered to be early to be told that DEA is a reliable tool to overcome such of this problem. And so, the researchers hope that for the further experiment should extending the range of the variant of the loads, and if possible, the experiment also added the load with conductive or inductive load, or both of them.

\section{ACKNOWLEDGEMENTS}

This research is funded by Universitas Airlangga through "Riset Kolaborasi Mitra Luar Negeri" grant. Therefore the first author is very gratefull to Universitas Airlangga.

\section{REFERENCES}

[1] A. U. Krismanto, N. Mithulananthan, and O. Krause, "Stability of Renewable Energy based Microgrid in Autonomous Operation," Sustain. Energy, Grids Networks, vol. 13, pp. 134-147, 2018, doi: 10.1016/j.segan.2017.12.009.

[2] R. Yan, N. -Masood, T. K. Saha, F. Bai, and H. Gu, "The Anatomy of the 2016 South Australia Blackout: A Catastrophic Event in a High Renewable Network," IEEE Trans. Power Syst., vol. 33, no. 5, pp. 5374-5388, 2018, doi: 10.1109/TPWRS.2018.2820150.

[3] Y. Yang, Q. Ye, L. J. Tung, M. Greenleaf, and H. Li, "Integrated size and energy management design of battery storage to enhance grid integration of large-scale PV power plants," IEEE Trans. Ind. Electron., vol. 65, no. 1, pp. 394-402, 2017, doi: 10.1109/TIE.2017.2721878.

[4] M. S. Islam and N. Mithulananthan, "PV based EV charging at universities using supplied historical PV output ramp," Renew. Energy, vol. 118, pp. 306-327, 2018.

[5] S. Suraya, P. Sujatha, and P. B. Kumar, "Contemporary control of DG integrated DVR for sag, swell and harmonic mitigation," Int. J. Electr. Comput. Eng., vol. 8, no. 5, p. 2721, 2018, doi: 10.11591/ijece.v8i5.pp.2721-2730.

[6] S. V. Madhavi and G. T. R. Das, "Variable structure control for an isolated boost converter used in fuel cell applications," Int. J. Electr. Comput. Eng., vol. 9, no. 6, p. 4493, 2019, doi: 10.11591/ijece.v9i6.pp4493-4506.

[7] K. Dhineshkumar, C. Subramani, A. Geetha, and C. Vimala, "Performance analysis of PV powered multilevel inverter,” Int. J. Electr. Comput. Eng., vol. 9, no. 2, p. 753, 2019, doi: 10.11591/ijece.v9i2.pp753-760.

[8] V. K. Kanakesh, D. B. Yelaverthi, A. Ghoshal, A. K. Rathore, and R. Mahanty, "Analysis and implementation of closed-loop control of electrolytic capacitor-less six-pulse dc-link bidirectional three-phase grid-tied inverter," IEEE Trans. Ind. Appl., vol. 54, no. 1, pp. 539-550, 2017, doi: 10.1109/TIA.2017.2757438.

[9] T. Siriborvornratanakul and M. Sugimoto, "Multiscale visual object detection for unsupervised ubiquitous projection based on a portable projector-camera system," in 2010 International Conference on Digital Image Computing: Techniques and Applications, 2010, pp. 623-628, doi: 10.1109/DICTA.2010.109.

[10] C. Kerdvibulvech, "Human hand motion recognition using an extended particle filter," in International Conference on Articulated Motion and Deformable Objects, 2014, pp. 71-80, doi: 10.1007/978-3-319-08849-5_8.

[11] R. K. Khadanga and J. K. Satapathy, "Time delay approach for PSS and SSSC based coordinated controller design using hybrid PSO-GSA algorithm," Int. J. Electr. Power Energy Syst., vol. 71, pp. 262-273, 2015, doi: 
10.1016/j.ijepes.2015.03.014.

[12] J. Zhou et al., "A multi-objective multi-population ant colony optimization for economic emission dispatch considering power system security," Appl. Math. Model., vol. 45, pp. 684-704, 2017, doi: 10.1016/j.apm.2017.01.001.

[13] H. K. Abdulkhader, J. Jacob, and A. T. Mathew, "Fractional-order lead-lag compensator-based multi-band power system stabiliser design using a hybrid dynamic GA-PSO algorithm," IET Gener. Transm. Distrib., vol. 12, no. 13, pp. 3248-3260, 2018, doi: 10.1049/iet-gtd.2017.1087.

[14] W. S. Sakr, R. A. El-Sehiemy, and A. M. Azmy, "Optimal allocation of TCSCs by adaptive DE algorithm," IET Gener. Transm. Distrib., vol. 10, no. 15, pp. 3844-3854, 2016, doi: 10.1049/iet-gtd.2016.0362.

[15] A. N. Arvindan, M. A. A. Mohamed, and R. AravindKumar, "Power Quality Analysis Of Six-And Twelve-Pulse Rectifiers As Series Cascaded Topologies Of The Three-Pulse Rectifier," in 2019 2nd International Conference on Power and Embedded Drive Control (ICPEDC), 2019, pp. 383-389, doi: 10.1109/ICPEDC47771.2019.9036517.

[16] H. Radmanesh and M. Saeidi, "Linear Modelling of Six Pulse Rectifier and Designee of Model Predictive Controller with Stability Analysis," Internasional Journal of Industrial Electronics Control and Optimization, vol. 3, no. 4, pp. 491-501, 2020.

[17] M. Rahnama, A. Vahedi, A. Mohammad-Alikhani, B. Nahid-Mobarakeh, and N. Takorabet, "Average value modeling of six-pulse diode rectifier considering unbalance conditions in supply voltage and impedance," Int. Trans. Electr. Energy Syst., vol. 30, no. 3, p. e12216, 2020, doi: 10.1002/2050-7038.12216.

[18] S. Suresh and S. Lal, "Modified differential evolution algorithm for contrast and brightness enhancement of satellite images," Appl. Soft Comput., vol. 61, no. Supplement C, pp. 622-641, 2017, doi: 10.1016/j.asoc.2017.08.019.

[19] W. Deng, H. Liu, J. Xu, H. Zhao, and Y. Song, "An improved quantum-inspired differential evolution algorithm for deep belief network,” IEEE Trans. Instrum. Meas., 2020, doi: 10.1109/TIM.2020.2983233.

[20] S.-K. Wang, "Coordinated parameter design of power system stabilizers and static synchronous compensator using gradual hybrid differential evaluation," Int. J. Electr. Power Energy Syst., vol. 81, pp. 165-174, 2016, doi: 10.1016/j.ijepes.2016.02.016.

[21] J. Bikanaria, S. K. Sharma, K. Parkh, and N. Dhakre, "Optimal tuning of PSS and STATCOM based controllers using differential evolution algorithm," in 2017 Recent Developments in Control, Automation \& Power Engineering (RDCAPE), 2017, pp. 421-426, doi: 10.1109/RDCAPE.2017.8358308.

[22] S. K. Mohapatra and B. S. Dash, "Coordinated Design of SSSC Based Power System Stabilizer Using Differential Evolution Algorithm," in 2015 International Conference on Computational Intelligence and Communication Networks (CICN), 2015, pp. 1476-1481, doi: 10.1109/CICN.2015.285.

[23] S. Wang, L. Yu, L. Wu, Y. Dong, and H. Wang, "An Improved Differential Evolution Algorithm for Optimal Location of Battery Swapping Stations Considering Multi-Type Electric Vehicle Scale Evolution,” IEEE Access, vol. 7, pp. 73020-73035, 2019, doi: 10.1109/ACCESS.2019.2919507.

[24] Z. Sun, N. Wang, D. Srinivasan, and Y. Bi, "Optimal tunning of type-2 fuzzy logic power system stabilizer based on differential evolution algorithm," Int. J. Electr. Power Energy Syst., vol. 62, pp. 19-28, 2014, doi: 10.1016/j.ijepes.2014.04.022.

[25] A. Swandaru, M. D. Rotaru, and J. K. Sykulski, "Intelligence based coordination of large scale grid-connected photovoltaic systems," in 2016 51st International Universities Power Engineering Conference (UPEC), 2016, pp. 1-6, doi: 10.1109/UPEC.2016.8114135.

[26] H. Setiadi, K. O. Jones, T. A. Nugroho, M. Abdillah, H. Trilaksana, and T. Amrillah, "Design of spark ignition engine speed control using bat algorithm," Int. J. Electr. Comput. Eng., vol. 11, no. 1, p. 794, 2021.

[27] M. Abdillah and H. Setiadi, "Advanced Wide-Area Monitoring System Design for Electrical Power System," Int. Rev. Model. Simulations (IREMOS); vol. 13, no. 6, Dec. 2020, [Online]. Available: https://www.praiseworthyprize.org/jsm/index.php?journal=iremos\&amp. 